\title{
is Research Square \\ Helical milling for making holes on carbon fiber reinforced polymer
}

\author{
Chunjie Su \\ Xiang Cheng ( $\nabla$ chengxsdut@163.com) \\ Shandong University of Technology \\ Xinhua Yan \\ Guangming Zheng \\ Yang Li \\ Zonggao Mu
}

\section{Research Article}

Keywords: Carbon fiber reinforced polymer, helical milling, delamination, burr, optimization

Posted Date: February 7th, 2022

DOI: https://doi.org/10.21203/rs.3.rs-1325884/v1

License: (c) (1) This work is licensed under a Creative Commons Attribution 4.0 International License. Read Full License 


\section{Abstract}

Carbon fiber reinforced polymer (CFRP) is widely used in various fields due to its excellent properties. However, machining defects such as delamination and burr are still the key issues constraining highquality hole making on CFRP. This research takes the helical milling process to make holes on CFRP and two kinds of cutting conditions (dry cutting and jet cold air assisted cutting) are explored. Tool wear, cutting force, delamination and surface morphology are taken as the main indices to be analyzed. The influences of key cutting parameters (spindle speed $n$, axial feed per tooth $f_{z a}$ and pitch $a_{\mathrm{p}}$ ) on cutting force and delamination are investigated and optimized. It turns out that the jet cold air condition is more suitable for helical milling of holes on CFRP with better qualities. The holes with smaller delamination factor and smoother surface are successfully fabricated based on the optimized cutting parameters.

\section{Introduction}

Carbon fiber is a potential reinforcing material. It has the advantages of high specific strength, high specific stiffness, good thermal conductivity, electrical conductivity, thermal stability and corrosion resistance. It has developed into the fourth largest aerospace structural material after aluminum, steel and titanium [1]. The processing of assembly holes required for mechanical connection is an indispensable part of aircraft assembly. In the hole processing, hole wall damage often occurs due to improper operation method and tool wear. Especially for anisotropic CFRP material, the hole processing is much more difficult than traditional metal materials [2]. Comparing with traditional drilling processing, the helical milling adopts completely different processing methods. The helical milling process includes three basic motions: the main motion with the milling cutter axis as the rotation axis, the rotation motion of the tool around the hole center and the feed motion along the axis. This special movement mode determines the advantages of the helical milling process, and eccentric processing is beneficial to improve the hole quality $[3,4]$.

Pereszlai et al. [5] carried out inclined helical milling experiments on CFRP and glass fiber reinforced polymer (GFRP) using uncoated carbide tools. The influence of inclined angle and pitch on axial cutting force were analyzed and discussed. The experimental results showed that the inclined angle had significant influence on the cutting force and burr. The inclined angle were suggested to increase as far as possible within the scope of the study. Amini et al. [6] conducted experimental studies on CFRP using tungsten carbide tools. The effects of process parameters such as cutting speed and feed rate on hole quality such as hole diameter, roundness, cylindricity and surface roughness were discussed. The experimental results showed that higher cutting speed could improve the hole roundness and cylindricity. But it had limited influence on the surface roughness. The cutting speed was more important than the feed speed in the helical milling process. Lower feed speed could obtain high hole quality. Geier et al. [7] developed a method to monitor and diagnose helical milling process by using digital image processing of uncut fiber features. The effectiveness and reliability of the method were verified by experiments. The holes processed by monitoring method had less uncut fibers than those by fixed process parameters. Ahmad et al. [8] conducted helical milling experiments on CFRP using coated and uncoated tools at fixed 
spindle speed and feed rate. The experimental results showed that the cutting performances of coated tools were better than that of uncoated tools. Zhou et al. [9] conducted helical milling experiments on CFRP/Ti laminated structure using special tools, and studied the influence of spindle speed, aperture ratio and tool-to-diameter ratio on hole diameter and roundness. The experimental results showed that the hole diameter at the exit of CFRP was the largest, and the trend remains unchanged with the increasing of holes number. Wang et al. [10] conducted many comparative studies on CFRP/Ti laminated structure, CFRP and titanium alloy laminates in the helical milling process in order to complete the drilling of CFRP/Ti laminated structure with larger thickness. The results showed that the cutting performances (cutting force, tool wear mode, hole quality) of helical milling laminated structure were different from that of single layer plate. Sun et al. [11] studied the damage mechanism of Ti/CFRP/Al laminated structure during processing through traditional drilling and helical milling. The experimental results showed that too high cutting temperature was the main cause of damage in helical milling. The cutting temperature generated by helical milling was lower than that by conventional drilling, which significantly improved the hole quality of CFRP. Wang et al. [12] compared the effects of cutting temperature on hole damage during helical milling of CFRP/Ti laminated structure with that of CFRP alone, and analyzed the cutting force, hole exit quality, hole wall quality and secondary surface quality of CFRP holes. The results showed that the titanium alloy layer had little effects on the cutting force, exit quality and wall quality of CFRP holes, but had great effects on the secondary surface quality of CFRP holes. The high cutting temperature might reduce the performances of CFRP resin matrix, and the fiber layer near the hole exit was the most serious. Li et al. [13] used coated milling cutters and uncoated milling cutters to perform helical milling holes on the Ti/CFRP laminated structure. The results showed that the uncoated milling cutters had the best cutting performances, the lowest cutting force, the highest hole quality and the smallest tool wear. Wang et al. [14] drilled holes in CFRP/Ti laminated structure, determined the influence of traditional drilling and helical milling on the geometric accuracy of holes, and studied the changes of aperture and roundness at different positions. The results showed that the geometric accuracy of the helical milling laminated structure in the titanium alloy layer hole was better, the roundness of the CFRP layer hole was better, and the roundness of the transition zone was smaller. Yang et al. [15] proposed a new anti-helical milling method to suppress delamination, which reduced the deformation of uncut material by increasing material stiffness. The effectiveness of the method was verified by experiments, which neither increased the existing delamination nor produced new delamination. Wang et al. [16] studied the cutting performance of CFRP helical milling, and discussed the influence of cutting parameters on cutting force by experiments. Then, the relationship between processing performances and cutting parameters was established by nonlinear fitting method. The cutting parameters of CFRP helical milling were optimized based on multi-objective genetic algorithm, and the effectiveness of the optimal cutting parameters was verified by experiments.

From literatures review, there is still a large space needing to be filled to fabricate high-quality holes on CFRP. Therefore, the effects of dry cutting condition and jet cold air condition on helical milling of holes on CFRP are studied and compared. Then, the cutting parameters are investigated and optimized. Finally, holes with high qualities are fabricated based on the research. 


\section{Experimental Procedure \\ 2.1 Experimental setup}

The machining center CarverPMS23_A8 is selected for the experiments, and the three-dimensional force measurement system (Kistler 9257B) is used to measure the cutting force, as shown in Fig. 1. The tool is double-edged PCD milling cutter with the diameter of $4 \mathrm{~mm}$. The detailed parameters of the milling cutter are shown in Table 1. The experimental material is T300 series CFRP, and its size is $80 \mathrm{~mm} \cdot 50 \mathrm{~mm} \cdot 5$ $\mathrm{mm}$. The material properties are shown in Table 2. During the cutting process, the tool continuously cut the material from the matrix material to produce a large amount of chips. The chip dust is dispersed in the air and easily enters the machine tool components, which affects the accuracy of the machine tool. At the same time, the chip dust is easily inhaled into the human body to endanger human health. Therefore, the dust removal device is set up to clean CFRP chips in time during the cutting process. Two cutting conditions are applied and compared. The dry cutting condition is without any additional cooling medium under the room temperature. The jet cold air condition is with additional low-temperature gas cooling of the cutting area using an adjustable cold air gun with a gas flow rate of $283 \mathrm{~L} / \mathrm{min}$ and a cooling temperature of $-5^{\circ} \mathrm{C}$.

Table 1

Parameters of milling cutter.

\begin{tabular}{|llll|}
\hline Edge diameter & Edge length & Total length & Edge number \\
\hline $4 \mathrm{~mm}$ & $5 \mathrm{~mm}$ & $70 \mathrm{~mm}$ & 2 \\
\hline
\end{tabular}

Table 2

CFRP material properties.

\begin{tabular}{|lllll|}
\hline Material type & $\begin{array}{l}\text { Matrix } \\
\text { material }\end{array}$ & $\begin{array}{l}\text { Layer } \\
\text { mode }\end{array}$ & $\begin{array}{l}\text { Carbon fiber volume } \\
\text { fraction }\end{array}$ & Stock thickness \\
\hline $\begin{array}{l}\text { T300 carbon } \\
\text { fiber }\end{array}$ & Epoxy resin & $0^{\circ} / 45^{\circ} / 90^{\circ}$ & $60 \pm 5 \%$ & $5 \mathrm{~mm}$ \\
\hline
\end{tabular}

In the experiment, the flank wear width of the milling cutter is selected as the evaluation index of tool wear, which refers to the distance from the outer edge contour of the milling cutter to the boundary of the wear area. Before using Quanta 250 scanning electron microscope to observe tool wear, PL-S40 ultrasonic cleaner is used to clean with 30 minutes and then dried with blowing air. The surface morphology of the hole is observed and analyzed by USB 200 digital tool microscope. The tool wear, cutting force and hole diameter in the delamination are measured 6 times, and the obtained experimental data are averaged.

\subsection{Experimental design}

In the process of helical milling, the rotational speed of milling cutter $n$ is usually much larger than the orbital speed $n_{\mathrm{g}}$, so it can be approximately considered that the cutting speed $v$ is proportional to the spindle speed of milling cutter $n$. Therefore, the cutting parameters of helical milling include spindle 
speed $n$, axial feed per tooth $f_{\text {za }}$ and pitch $a_{\mathrm{p}}$. Undeformed chip formation is always changing from the beginning to the steady helical milling state and then the undeformed chip formation remains unchanged. Fig. 2 shows the undeformed chips at the steady state, where $D_{\mathrm{t}}$ is cutter diameter [17].

The experimental design selects three important influence factors, and each factor selects four levels. According to the number of factors and the number of levels, the $L_{16}\left(4^{5}\right)$ orthogonal table is selected without considering the interaction between factors. The designed orthogonal experimental table is shown in Table 3.

Table 3

Designed orthogonal experimental table.

\begin{tabular}{|llll|}
\hline Experimental & Factor & & \\
\cline { 2 - 3 } & $\begin{array}{l}\text { Spindle speed } \\
n(\mathrm{rpm})\end{array}$ & $\begin{array}{l}\text { Axial feed per tooth } \\
\boldsymbol{f}_{\text {za }}(\mathrm{mm} / \mathbf{z})\end{array}$ & $\begin{array}{l}\text { Pitch } \\
\boldsymbol{a}_{\mathrm{p}}(\mathrm{mm})\end{array}$ \\
\hline 1 & 8000 & 0.02 & 0.2 \\
\hline 2 & 8000 & 0.04 & 0.4 \\
\hline 3 & 8000 & 0.06 & 0.6 \\
\hline 4 & 8000 & 0.08 & 0.8 \\
\hline 5 & 12000 & 0.02 & 0.4 \\
\hline 6 & 12000 & 0.04 & 0.2 \\
\hline 7 & 12000 & 0.06 & 0.8 \\
\hline 8 & 12000 & 0.08 & 0.6 \\
\hline 9 & 16000 & 0.02 & 0.6 \\
\hline 10 & 16000 & 0.04 & 0.8 \\
\hline 11 & 16000 & 0.06 & 0.2 \\
\hline 12 & 16000 & 0.08 & 0.4 \\
\hline 13 & 20000 & 0.02 & 0.8 \\
\hline 14 & 20000 & 0.04 & 0.6 \\
\hline 15 & 20000 & 0.06 & 0.4 \\
\hline 16 & 20000 & 0.08 & \\
\hline
\end{tabular}

\section{Experimental Results And Discussion}




\subsection{Tool wear}

The helical milling is a semi-closed machining. A large amount of heat generated during the cutting process is not easily taken away by chips and tools, which is easy to cause tool wear. Tool wear not only affects hole quality, but also affects processing efficiency and increases processing cost [18]. After the experiment is completed, the tool wear is observed, and the tool wear forms under the two cutting conditions are shown in Fig. 3.

Figure 3 presents the tool wear forms under two cutting conditions, where the main wear forms are microchipping, corner rounding and adhesion. Under jet cold air condition, the corner rounding is relatively serious, and the cutting edge is slightly chipped. Helical milling is an intermittent cutting, the cutting edge is subjected to continuous alternating loads. Due to the brittle nature of PCD material, micro-chipping is prone to occur at the cutting edge, especially when the temperature gradient is large. The corner rounding is mainly from micro chipping and the frictions between the tool and the workpiece. In addition, the chip is easy to bond on the tool surface under the combined thermal-force actions.

In the process of CFRP helical milling, the flank and transverse edge of the tool have different degrees of wear, and the flank wear is the main wear form $[19,20]$. Therefore, the flank wear is measured and analyzed. After the experiment is completed, in order to further determine the influence of two cutting conditions on tool wear, the trend of tool wear changing with the holes number is recorded as shown in Fig. 4.

As shown in Fig. 4, with the increase of the holes number, the tools under both cutting conditions appear different degrees of wear, and the wear values show an upward trend. On the one hand, with the increase of the holes number, the scratching effect on the tool flank is continuously increased. In addition, during the helical milling process, there are more carbon powder particles scratching the tool resulting in increased tool wear. On the other hand, due to poor thermal conductivity of the matrix, more and more cutting heat accumulates. This further increases the tool wear.

Compared with dry cutting condition, tool wear is more serious under jet cold air condition. With the increase of the machined holes, the cutting temperature of the tool in helical milling continuously increases resulting in a large change in the temperature gradient of the cutting edge in jet cold air cutting condition. According to Fig. 3, the micro-chipping and corner rounding is relatively serious under jet cold air condition. Therefore, the tool is more occur to wear than the tool under dry cutting condition.

\subsection{Cutting force}

The magnitude and fluctuation of cutting force directly reflect the machining state and affect the surface quality [21, 22]. In the hole processing on CFRP, the cutting force directly affects the hole quality, which is the main factor causing the material delamination around the hole wall, the tearing of the entrance and exit of the hole, the burr and other major defects [23]. The resultant force is collected as shown in Eq. (1). 


$$
F=\left(F \mathrm{x}^{2}+F \mathrm{y}^{2}+F \mathrm{z}^{2}\right)^{\frac{1}{2}}
$$

1

The cutting force obtained after processing the data is shown in Fig. 5.

Figure 5 shows the cutting force created under dry cutting condition and jet cold air condition. It can be seen from Fig. 4 that the cutting force under jet cold air condition is larger than that under dry cutting condition. This is because the matrix material of CFRP is a kind of resins, which determines the final performances of CFRP, such as structural strength and structural stiffness. The resin becomes harder after low temperature cooling, so that the strength of CFRP increase with the decrease of temperature. It will lead to the increase of cutting forces.

\subsection{Delamination}

Among many machining defects, delamination is one that has a fatal effect on the hole quality $[24,25]$. It refers to the CFRP interlayer stress or manufacturing defects caused by delamination between the composite layer separation failure phenomenon. It causes a decrease in the tensile strength of the CFRP laminates. Under the working conditions of alternating fatigue load, delamination further expands and it will ultimately lead to early termination of service life of CFRP components. The delamination diagram is shown in Fig. 6.

In the process of helical milling, when the tool begins to contact with the workpiece material and the main cutting edge is not fully cut into the workpiece material, the cutting force pushes the removed material into the helical groove. These materials rise along the helical groove surface before cutting, resulting in an upward peeling force. The peeling force separates the unresected region in the upper layer, namely the peeling delamination. On the other hand, when the tool is about to cut out the material, because the number of remaining uncut layers of the material is less and less, if the cutting force exceeds the interlayer bonding strength of the material, debonding occurs between the layers around the exit, resulting in push-out delamination. The delamination occurs in the interlayer region, so it not only depends on the properties of the fiber, but also depends on the properties of the resin [26]. CFRP laminates are delaminated on both the entrance side and the exit side in helical milling. In this study, the entrance side is focused and studied considering the peeling forces.

The ratio of the maximum stratified diameter $D_{\max }$ to the nominal diameter $D_{\text {norm }}$ of the hole $F_{\mathrm{d}}$ is taken as the standard to measure the delamination degree [27], namely the diameter delamination factor, which is referred to as the delamination factor $F_{\mathrm{d}}$. The formula is shown in Eq. (2).

$$
F \mathrm{~d}=\frac{\text { Dmax }}{\text { Dnorm }}
$$

2

After the experiment, the diameter of the hole processing under two cutting conditions is measured. The delamination factor obtained after processing the data is shown in Fig. 7. 
Figure 7 is the delamination factor of each group under dry cutting condition and jet cold air condition. It can be seen from Figure 7 that the delamination factor of hole processing under jet cold air condition is smaller than that under dry cutting condition, indicating that the delamination phenomenon at the hole inlet is effectively suppressed under jet cold air condition. Under jet cold air condition, due to the large cutting force, the material can be more completely removed and pushed into the helical groove resulting a smaller peeling force than that under dry cutting condition. In addition, under jet cold air condition, the fiber extrusion in the helical milling process is inhibited due to the low temperature. The extension distance of the fiber crack in the axial and radial directions is reduced. Therefore, the hole surface is smoother and the delamination factor is smaller.

The delamination factor of the sixteenth hole is the largest with the cutting parameters of $n=20000 \mathrm{rpm}$, $f_{\mathrm{za}}=0.08 \mathrm{~mm} / \mathrm{z}, a_{\mathrm{p}}=0.2 \mathrm{~mm}$. The delamination factor is 1.145 and 1.148 under jet cold air condition and under dry cutting condition, respectively. The fifth hole has the smallest delamination factor with the cutting parameters of $n=12000 \mathrm{rpm}, f_{\mathrm{za}}=0.02 \mathrm{~mm} / \mathrm{z}, a_{\mathrm{p}}=0.4 \mathrm{~mm}$. The delamination factor is 1.128 and 1.130 under jet cold air condition and under dry cutting condition, respectively.

\subsection{Surface morphology}

Surface morphology is a key factor affecting the performances and reliability of materials, which can further reflect the processing quality of workpiece [28]. Based on the analysis in chapter 3.3, the delamination factor of the sixteenth and the fifth holes are the largest and the smallest, respectively. The surface morphology of the corresponding processing hole is shown in Fig. 8 and Fig. 9.

After the experiment, no obvious surface fiber burrs and tears occurred on the entrance surface of the processing holes under two cutting conditions. However, it can be observed in Fig. $8 \mathrm{a}$ that there is chip dust adsorption on the surface at the outlet of the processing hole under dry cutting condition. Fig. 8 and Fig. 9 show that the processing holes surfaces under jet cold air condition is smoother than that under dry cutting condition. The reason is that low temperature cooling improves the strength of the resin and the brittleness of the fiber, thereby makes the surface of the CFRP material smoother. Therefore, the hole quality under jet cold air condition is better than that under dry cutting condition.

\section{Optimized Verification Experiment}

Based on the above analysis, the hole quality under jet cold air condition is better than that under dry cutting condition. Therefore, the optimized verification experiment only needs to be carried out under jet cold air condition. The cutting force values and delamination factor values of each group under jet cold air condition are analyzed by range method. The analysis results are shown in Table 4 and Table 5 . In the table, $K_{\mathrm{i}}$ is the sum of the experimental results corresponding to any level, $\mathrm{i}$ is the level, and $k_{\mathrm{i}}$ is the average value of the results at any level. The range $R$ corresponding to each column factor is $R=\max \left\{k_{1}\right.$, $\left.k_{2}, k_{3}, k_{4}\right\}-\min \left\{k_{1}, k_{2}, k_{3}, k_{4}\right\}$. The larger the $R$ value is, the larger the influence of cutting parameters on the index is. 
The range analysis result of the cutting force is shown in Table 4. According to the magnitude of the range $R$, it can be analyzed that the influence of the axial feed per tooth $f_{\mathrm{za}}$ on the cutting force is significantly larger than that of the pitch $a_{\mathrm{p}}$ and the spindle speed $n$. The axial feed per tooth $f_{\mathrm{za}}$ and pitch $a_{\mathrm{p}}$ have the same trend to the cutting force. With the increase of the axial feed per tooth $f_{\mathrm{za}}$ and pitch $a_{\mathrm{p}}$, the cutting force gradually increases. With the increase of spindle speed $n$, the cutting force gradually decreases. Considering the influence of various factors on the cutting force, the optimal parameter combination is selected as $n=20000 \mathrm{rpm}, f_{\mathrm{za}}=0.02 \mathrm{~mm} / \mathrm{z}, a_{\mathrm{p}}=0.2 \mathrm{~mm}$.

Table 4

Cutting force range analysis result.

\begin{tabular}{|llll|}
\hline Project & $\boldsymbol{n}$ & $\boldsymbol{f}_{\text {za }}$ & $\boldsymbol{a}_{\mathbf{p}}$ \\
\hline$K_{1}$ & 336.6 & 208.5 & 306.1 \\
\hline$K_{2}$ & 326.9 & 275.2 & 320.8 \\
\hline$K_{3}$ & 325.2 & 323.7 & 336.6 \\
\hline$K_{4}$ & 318.4 & 499.7 & 343.6 \\
\hline$k_{1}$ & 84.2 & 52.1 & 76.5 \\
\hline$k_{2}$ & 81.7 & 68.8 & 80.2 \\
\hline$k_{3}$ & 81.3 & 80.9 & 84.2 \\
\hline$k_{4}$ & 79.6 & 124.9 & 85.9 \\
\hline$R$ & 4.6 & 72.8 & 9.4 \\
\hline
\end{tabular}

The range analysis result of delamination is shown in Table 5. According to the range $R$, the influence of spindle speed $n$ on delamination is larger than that of the axial feed per tooth $f_{\text {za }}$ and pitch $a_{\mathrm{p}}$. With the increase of spindle speed $n$, the delamination factor decreases first and then increases. And the axial feed per tooth $f_{\mathrm{za}}$ and pitch $a_{\mathrm{p}}$ have the same trend for delamination. With the increase of the axial feed per tooth $f_{\mathrm{za}}$ and pitch $a_{\mathrm{p}}$, the delamination factor gradually increases. Considering the influence of various factors on delamination, the optimal parameter combination is selected as $n=12000 \mathrm{rpm}, f_{\mathrm{za}}=0.02$ $\mathrm{mm} / \mathrm{z}, a_{\mathrm{p}}=0.2 \mathrm{~mm}$. 
Table 5

Delamination range analysis result.

\begin{tabular}{|llll|}
\hline Project & $\boldsymbol{n}$ & $\boldsymbol{f}_{\text {za }}$ & $\boldsymbol{a}_{\mathrm{p}}$ \\
\hline$K_{1}$ & 4.544 & 4.530 & 4.542 \\
\hline$K_{2}$ & 4.531 & 4.541 & 4.547 \\
\hline$K_{3}$ & 4.552 & 4.557 & 4.552 \\
\hline$K_{4}$ & 4.570 & 4.569 & 4.556 \\
\hline$k_{1}$ & 1.136 & 1.133 & 1.136 \\
\hline$k_{2}$ & 1.133 & 1.135 & 1.137 \\
\hline$k_{3}$ & 1.138 & 1.139 & 1.138 \\
\hline$k_{4}$ & 1.143 & 1.142 & 1.139 \\
\hline$R$ & 0.01 & 0.009 & 0.003 \\
\hline
\end{tabular}

In order to obtain good hole quality, based on the orthogonal experimental results, each index is analyzed according to the range analysis results. For the cutting force and delamination indexes, the optimal values of the axial feed per tooth $f_{\mathrm{za}}$ and pitch $a_{\mathrm{p}}$ are $f_{\mathrm{za}}=0.02 \mathrm{~mm} / \mathrm{z}, a_{\mathrm{p}}=0.2 \mathrm{~mm}$. The optimal value of spindle speed $n$ for cutting force index is $n=20000 \mathrm{rpm}$, and the optimal value for delamination index is $n=12000 \mathrm{rpm}$. Considering that the influence of delamination on the hole quality is relatively large, and the influence of cutting force on the hole quality is relatively small, the optimal value of delamination index is given priority, which is $n=12000 \mathrm{rpm}$. To sum up, the final optimal parameter combination is $n=$ $12000 \mathrm{rpm}, f_{\mathrm{za}}=0.02 \mathrm{~mm} / \mathrm{z}, a_{\mathrm{p}}=0.2 \mathrm{~mm}$. The verification experiment is carried out with the optimal parameter combination. The effects of the created holes on CFRP are shown in Fig. 10. The measured delamination factor is 1.125 , and the processing holes surface is relatively smooth. The hole quality after optimized verification experiment is good.

\section{Conclusions}

In this research, two cutting conditions (dry cutting condition and jet cold air condition) are used to conduct helical milling studies on CFRP. Comparisons have been conducted from the perspective of tool wear, cutting force, delamination and surface morphology in helical milling of holes on CFRP. The main conclusions are summarized as follows.

(1) Both of the tool wear and the cutting force are smaller under dry cutting condition than that under jet cold air condition. However, under the latter condition, delamination can be better suppressed and better surface morphology can be achieved. 
(2) The impact sequence of cutting parameters on the cutting force from large to small is $f_{\mathrm{za}}$, $a_{\mathrm{p}}$, and $n$. The impact sequence of cutting parameters on the delamination from large to small is $n, f_{\mathrm{za}}$, and $a_{\mathrm{p}}$.

(3) The optimal parameter combination is $n=12000 \mathrm{rpm}, f_{\mathrm{za}}=0.02 \mathrm{~mm} / \mathrm{z}, a_{\mathrm{p}}=0.2 \mathrm{~mm}$ under jet cold air condition. Holes with smaller delamination factor and smoother are successfully fabricated on CFRP.

\section{Declarations}

Funding The research is financially supported by the Major Engineering Project of New and Old Kinetic Energy Conversion of Shandong Province, and the Natural Science Foundation of Shandong Province (ZR2020ME157).

Data availability All data generated or analyzed during this study are included in this published article.

\section{Compliance with ethical standards}

Conflict of interest The authors declare that they have no conflicts of interest.

Ethics approval Not applicable.

Consent to participate Not applicable.

Consent for publication Not applicable.

\section{References}

1. Teti R (2002) Machining of Composite Materials. CIRP Ann-Manuf Techn 51(2):611-634

2. Hocheng H, Puw HY (1992) On drilling characteristics of fiber-reinforced thermoset and thermoplastics. Int J Mach Tool Manu 32(4):583-592

3. Denkena B, Boehnke D, Dege JH (2008) Helical milling of CFRP-titanium layer compounds. CIRP J Manuf Sci Tec 1(2):64-69

4. Wang GD, Suntoo D, Li N, Peng T, Li YC (2018) Experimental research in CFRP/Ti stack through different helical milling strategies. Int J Adv Manuf Tech 98(17):3251-3267

5. Pereszlai C, Geier N, Poór DI, Balázs BZ, Póka G (2021) Drilling fibre reinforced polymer composites (CFRP and GFRP): An analysis of the cutting force of the tilted helical milling process.Compos Struct262

6. Amini S, Baraheni M, Hakimi E (2019) Enhancing dimensional accuracy and surface integrity by helical milling of carbon fiber reinforced polymers. Int J Lightw Mater Manuf 2(4):362-372

7. Geier N, Póka G, Pereszlai C (2019) Monitoring of orbital drilling process in CFRP based on digital image processing of characteristics of uncut fibres. Pro CIRP 85:165-170 
8. Ahmad N, Khan SA, Raza SF (2019) Influence of hole diameter, workpiece thickness, and tool surface condition on machinability of CFRP composites in orbital drilling: a case of workpiece rotation. Int J Adv Manuf Tech 103(5-8):2007-2015

9. Zhou L, Ke YL, Dong HY, Chen ZP, Gao KY (2016) Hole diameter variation and roundness in dry orbital drilling of CFRP/Ti stacks. Int J Adv Manuf Tech 87(1-4):811-824

10. Wang HY, Qin XD, Li H, Tan YQ (2016) A comparative study on helical milling of CFRP/Ti stacks and its individual layers. Int J Adv Manuf Tech 86(5-8):1973-1983

11. Sun L, Gao H, Wang B, Bao YJ, Wang MH, Ma SJ (2020) Mechanism of reduction of damage during helical milling of titanium/CFRP/aluminium stacks. Int J Adv Manuf Tech 107:4741-4753

12. Wang $B$, Wang YF, Zhao H, Wang HM, Sun $L$ (2021) Mechanisms and evaluation of the influence of cutting temperature on the damage of CFRP by helical milling. Int J Adv Manuf Tech 113:1887-1897

13. Li SP, Qin XD, Jin Y, Sun D, Li YH (2018) A comparative study of hole-making performance by coated and uncoated WC/Co cutters in helical milling of Ti/CFRP stacks. Spr Lon 94(5):2645-2658

14. Wang B, Zhao H, Zhang F, Wang HM, Zheng YH (2021) Comparison of the geometric accuracy of holes made in CFRP/Ti laminate by drilling and helical milling. Int J Adv Manuf Tech 112:33433350

15. Yang GL, Dong ZG, Gao S, Yan B, Kang YK, Guo DM (2020) A novel reverse helical milling process for reducing push-out delamination of CFRP.Compos Struct253

16. Wang HY, Qin XD, Wu DX, Song AJ (2018) Optimization of Cutting Parameters in Helical Milling of Carbon Fiber Reinforced Polymer. Trans TJU 24(01):91-100

17. Cheng X, Zhang X, Tian YB, Zheng GM, Yang XH (2018) Study on micro helical milling of small holes with flat end mills. Int J Adv Manuf Tech 97(5-8):3119-3128

18. Chen T, Wang CH, Xiang JP, Wang YS (2020) Study on tool wear mechanism and cutting performance in helical milling of CFRP with stepped bi-directional milling cutters. Int J Adv Manuf Tech 111(9):2441-2448

19. Park KH, Beal A, Kim D, Kwon P, Lantrip J (2011) Tool wear in drilling of composite/titanium stacks using carbide and polycrystalline diamond tools. Wear 271(11):2826-2835

20. Rawat S, Attia H (2009) Wear mechanisms and tool life management of WC-Co drills during dry high speed drilling of woven carbon fibre composites. Wear 267(5-8):1022-1030

21. Zhang CL, Feng PF, Wu ZJ, Yu DW (2011) Mathematical modeling and experimental research for cutting force in rotary ultrasonic drilling. Chin J Mech Eng-en 47(15):149-155

22. Zhang S, Jiao F, Wang X, Niu Y (2021) Modeling of cutting forces in helical milling of unidirectional CFRP considering carbon fiber fracture. J Manuf Process 68(PA):1495-1508

23. Iliescu D, Gehin D, Gutierrez ME, Girot F (2009) Modeling and tool wear in drilling of CFRP. Int J Mach Tool Manu 50(2):204-213

24. Jung JP, Kim GW, Lee KY (2004) Critical thrust force at delamination propagation during drilling of angle-ply laminates. Compos Struct 68(4):391-397 
25. Durão LMP, Tavares JMRS, Albuquerque VHC, Gonçalves DJS (2013) Damage evaluation of drilled carbon/epoxy laminates based on area assessment methods. Compos Struct 96:576-583

26. Durão LMP, Gonçalves DJS, Tavares JMRS et al (2009) Drilling tool geometry evaluation for reinforced composite laminates. Compos Struct 92(7):576-583

27. Jia ZY, Bai Y, Wang FJ, Ma JW, Cheng D, Zhang ZB (2019) Effect of drill flute direction on delamination at the exit in drilling Carbon Fiber Reinforced Plastic. Polym Compos 40(S2):14341440

28. Yang XM, Cheng X, Li Y, Zheng GM, Xu RF (2020) Machinability investigation and sustainability analysis of minimum quantity lubrication-assisted micro-milling process. P I Mech Eng B-J Eng 234(11):1388-1401

\section{Figures}

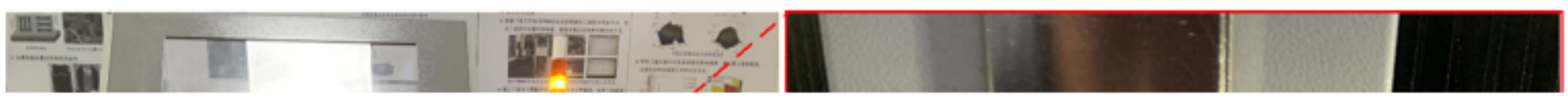

\section{Figure 1}

Experimental setup. 
Finished hole surface Cutter axial feed direction

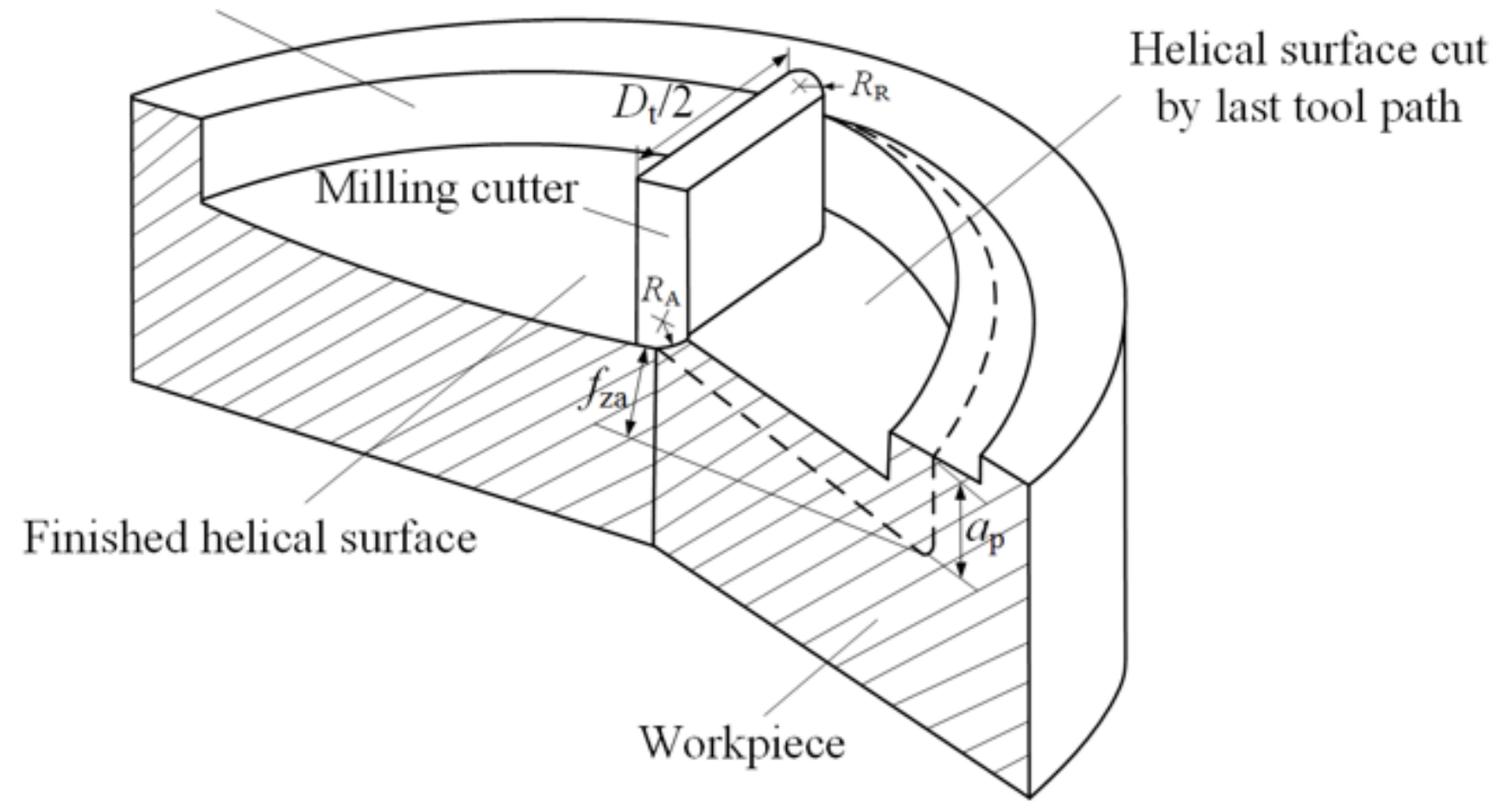

Figure 2

Undeformed chip formations in helical milling at the steady state [17].
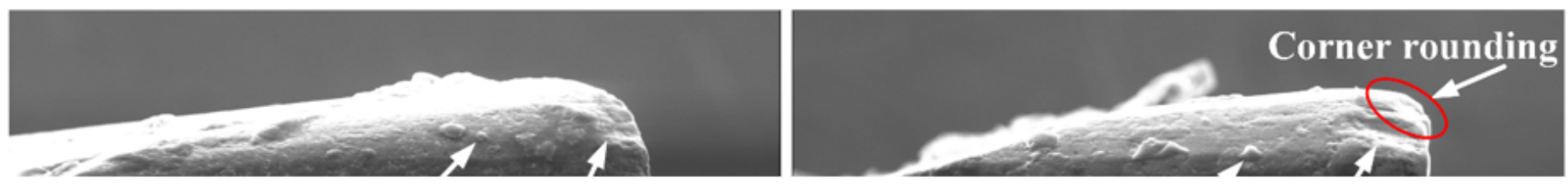

Figure 3 
Tool wear forms under two cutting conditions.

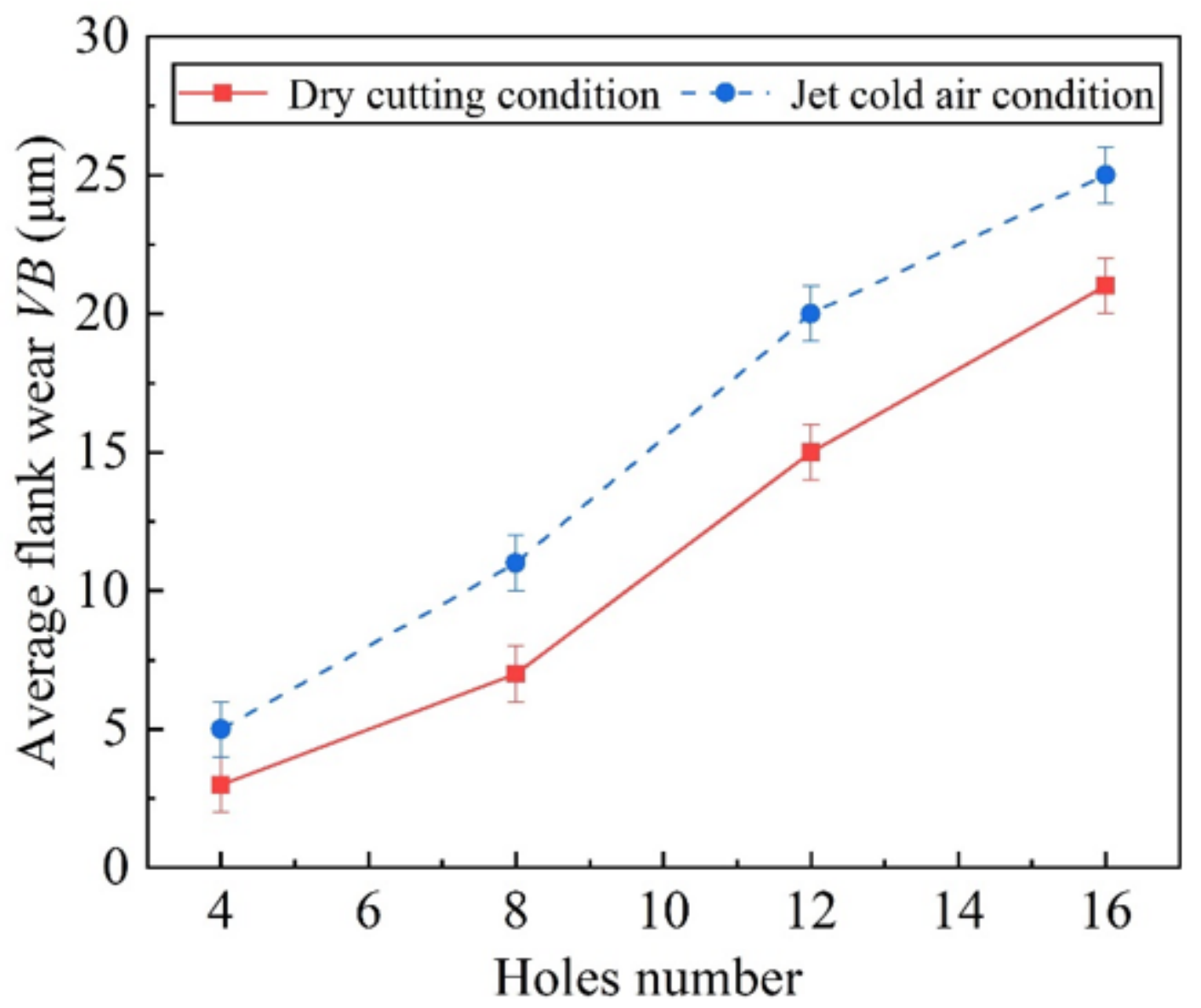

Figure 4

Trend of tool wear under two cutting conditions. 


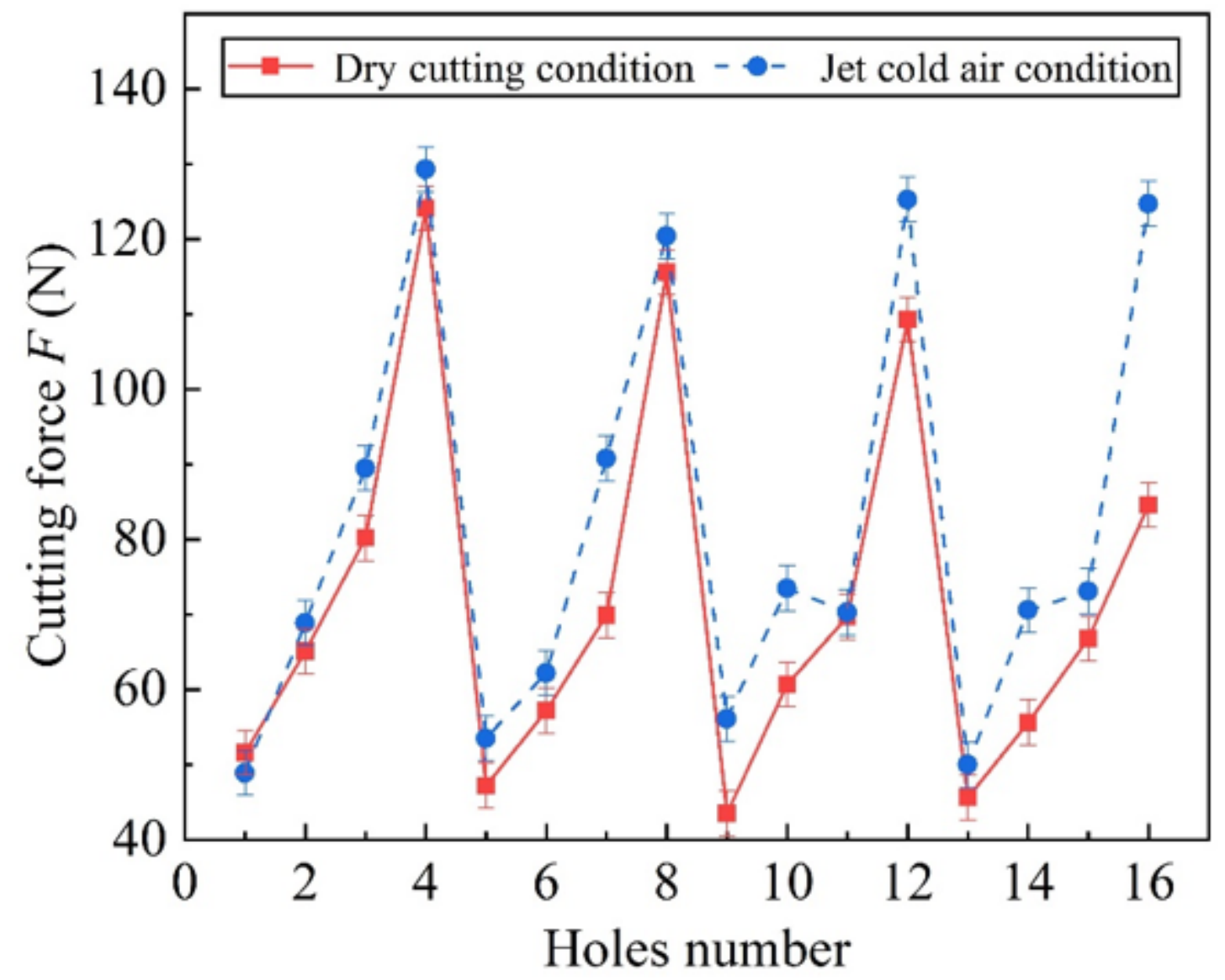

Figure 5

Cutting force under two cutting conditions. 


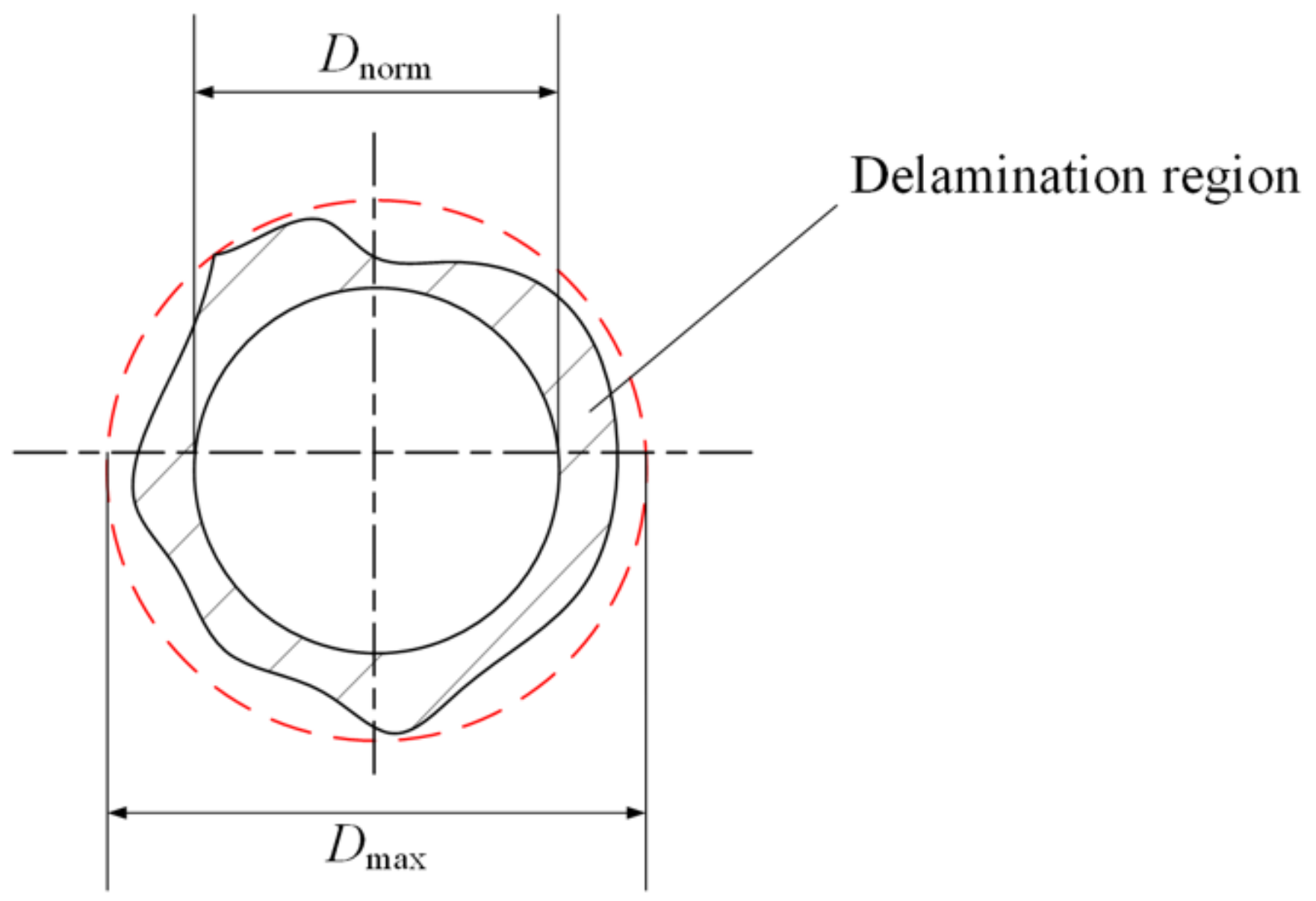

Figure 6

The delamination diagram.

Figure 7

Delamination factor under two cutting conditions. 


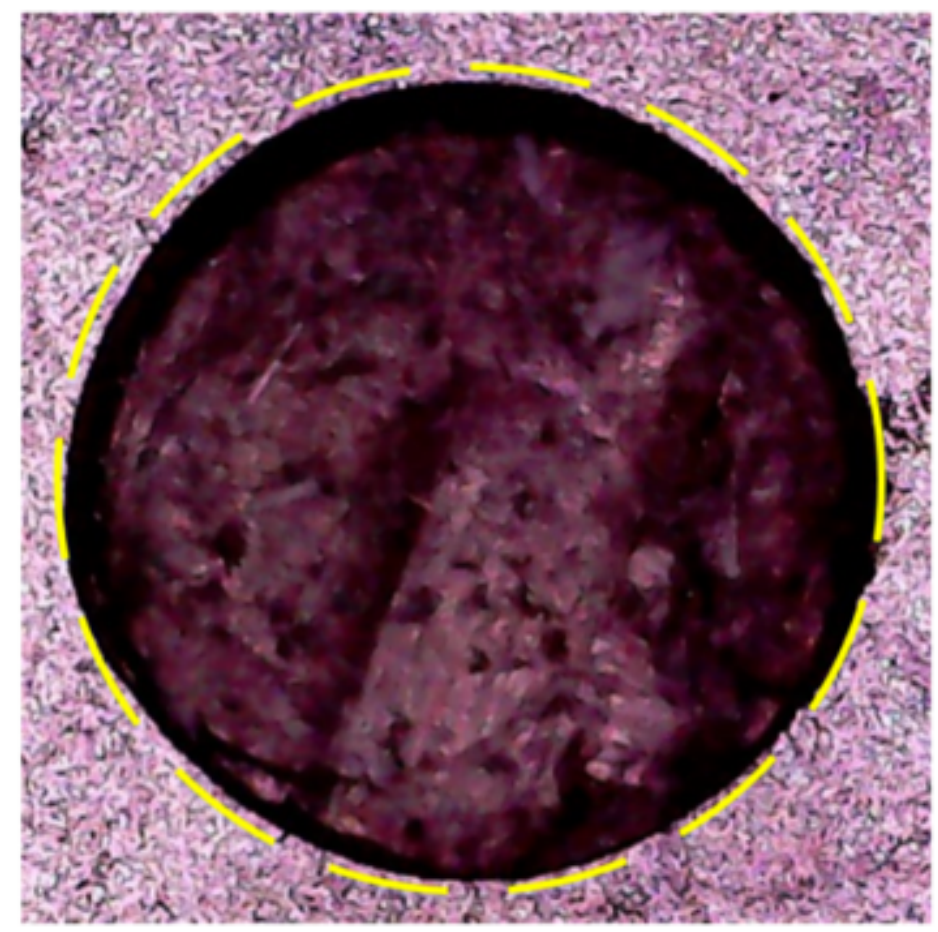

(a) Dry cutting condition

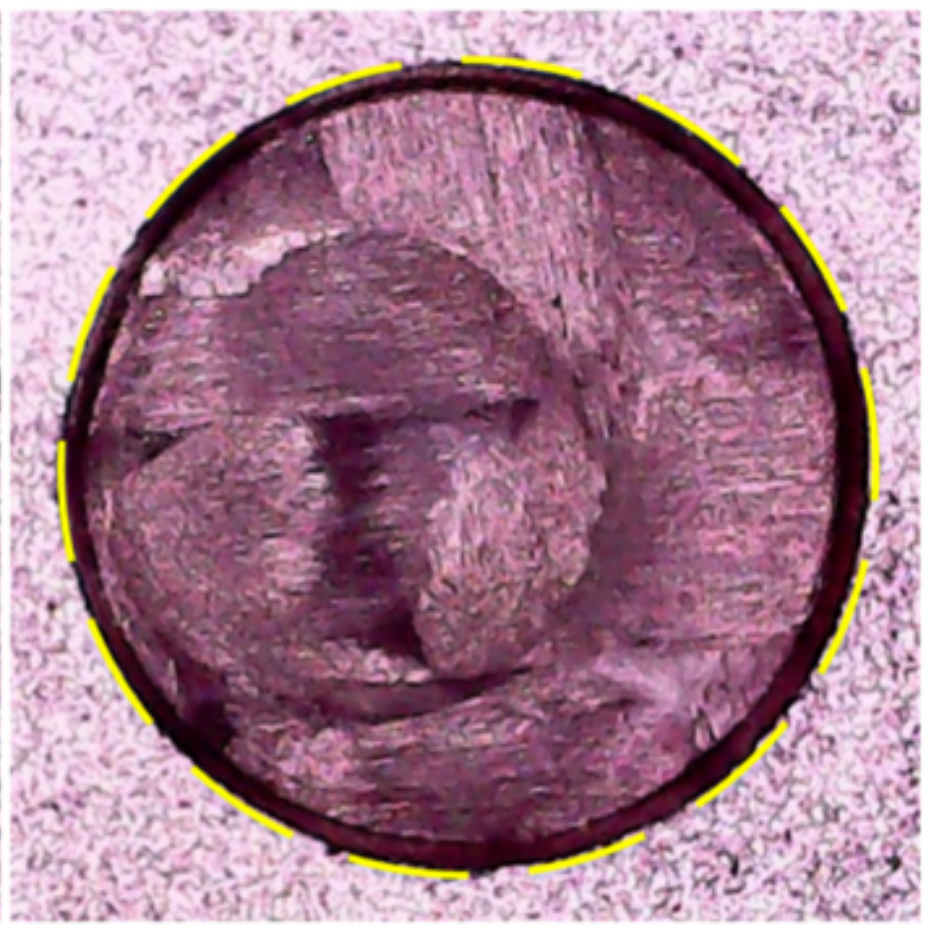

(b) Jet cold air condition

\section{Figure 8}

Surface morphology of the sixteenth hole. 
Figure 9

Surface morphology of the fifth hole.

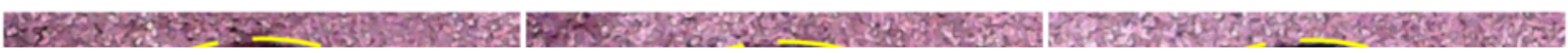

Figure 10

Optimized verification experimental holes. 